\title{
GC-MS Analysis of Bioactive Phytochemicals Present in Ethanolic Extracts of Leaves of Annona muricata: A Further Evidence for Its Medicinal Diversity
}

\author{
Yahaya Gavamukulya ${ }^{1,2^{*}}$, Faten Abou-Elella ${ }^{3}$, Fred Wamunyokoli ${ }^{1,4}$ and Hany A El-Shemy ${ }^{1,3,5}$

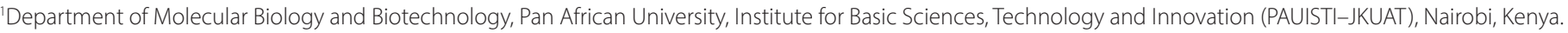 \\ 2Department of Biochemistry and Molecular Biology, Faculty of Health Sciences, Busitema University, Mbale Regional Referal Hospital, Uganda. \\ ${ }^{3}$ Department of Biochemistry, Faculty of Agriculture, Cairo University, 12613 Giza, Egypt. \\ 4 Department of Biochemistry, Jomo Kenyatta University of Agriculture and Technology (JKUAT), Nairobi, Kenya. \\ ${ }^{5}$ Department of Biochemistry, Faculty of Agriculture Research Park (FARP) and Faculty of Agriculture, Cairo University, 12613 Giza, Egypt.
}

\begin{abstract}
Background: Folk medicine has taken an important place especially in developing countries where limited health services are available. However, the absence of scientific evaluation of medicinal plants may cause serious adverse effects. Objective: To analyze the phytochemical composition of the ethanolic extracts of leaves of Annona muricata using gas chromatography mass spectroscopy (GC-MS). Materials and methods: GC-MS Analysis was used. Results: The GC-MS Analysis revealed 25 constituents of which 12 of the compounds were identified. The major constituents were two unidentified compounds with percentage peak areas of $23.51 \%$ and $16.8 \%$. Of the identified compounds, the outstanding in composition were 7-Tetradecenal, (Z) (peak area 9.39\%), n-Hexadecanoic acid (peak area $7.12 \%)$, Oleyl Alcohol (peak area 6.15\%), Phytol (peak area 5.61\%), cis, cis, cis-7,10,13-Hexadecatrienal (peak area 4.26\%), 2-Pentadecanol (peak area 3.93\%), 9,12-Octadecadienoic acid, ethyl ester (peak area $3.21 \%$ ), 1,2-Benzenedicarboxylic acid, butyl octyl ester (peak area 2.67\%), and 1,E11, Z-13-Octadecatriene (peak area 2.15\%), while the rest had less than $2 \%$ composition by peak area. Conclusion: The current study suggests that ethanolic extracts of leaves of Annona muricata are a potent therapeutic agent and paves the way for the development of several treatment regimens based on compounds from this extract.
\end{abstract}

Key words: Annona muricata, Ethanolic extracts, GC-MS, Medicinal diversity, Phytochemicals.

\section{SUMMARY}

- Annona muricata is widely used to treat various diseases.

- Objective: To conduct a GC-MS Analysis on ethanolic leaves extracts 25 compounds were generated, 12 compounds were identified, 13 were not.

- The major constituents were two unidentified compounds with percentage peak areas of $23.51 \%$ and $16.8 \%$.

- Identified compounds included: 7-Tetradecenal, (Z) (peak area 9.39\%), nHexadecanoic acid (peak area 7.12\%), Oleryl Alcohol (peak area 6.15\%), Phytol (peak area $5.61 \%$ ) cis, cis, cis-7,10,13-Hexadecatrienal (peak area $4.26 \%$ ),
2-Pentadecanol (peak area 3.93\%), 9,12-Octadecadienoic acid, ethyl ester (peak area 3.21\%), 1,2-Benzenedicarboxylic acid, butyl octyl ester (peak area $2.67 \%$ ), 1,E-11,Z-13-Octadecatriene (peak area 2.15\%). The rest had less than $2 \%$ composition by peak area.

- All identified compounds of known health benefits. Further studies needed on the plant's therapeutic value.

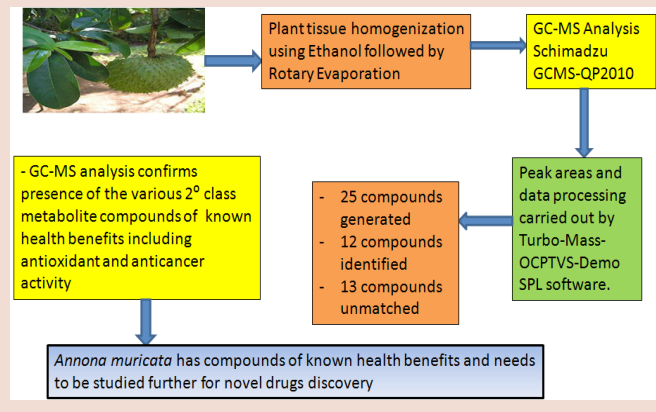

PICTORIAL ABSTRACT

Abbreviations used: GC-MS: Gas Chromatography Mass Spectroscopy, TIC: Total Ion Chromatogram.

Correspondence:

Yahaya Gavamukulya, Department of Biochemistry and Molecular Biology, Faculty of Health Sciences, Busitema University, Mbale Regional Referal Hospital, Uganda.

Phone no: +256775869783

Email: gavayahya@yahoo.com

DOI : $10.5530 /$ pj.2015.5.9

\section{INTRODUCTION}

Plant use in treatment of diseases is as old as civilization, ${ }^{1,2}$ and complementary medicine is still a major part of habitual treatments of different maladies. ${ }^{2,3}$ Generally, complementary medicine has a long history of serving people all over the world. ${ }^{4,5}$ In recent times and due to historical, cultural, and other reasons, folk medicine has taken an important place especially in developing countries where limited health services are available. However, the absence of scientific evaluation of medicinal plants may cause serious adverse effects. ${ }^{3,6,7}$

Natural products are extremely an important source of medicinal agents. Although there are some new approaches to drug discovery, such as combinatorial chemistry and computer based molecular modeling design, none of them can replace the importance of natural products in drug discovery and development. ${ }^{8}$ Many non-natural, synthetic drugs cause severe side effects that were not acceptable except as treatments of last resort for terminal diseases such as cancer and that the metabolites discovered in medicinal plants may avoid the side effect of synthetic drugs, because they must accumulate within living cells. ${ }^{5}$

Annona muricata L commonly known as Graviola or Soursop belongs to the family of Annonaceae and is the most tropical semi deciduous tree with the largest fruits of the Annona genus. It is a typical tropical tree with heart shaped edible fruits and widely distributed and native to SubSaharan Africa countries that lie within the tropics including Uganda. The leaves are lanceolate with glossy and dark green in color and had been traditionally used to treat headaches, hypertension, cough, asthma and used as antispasmodic, sedative and nervine for heart condition,, 10 as well as cancer. It is widely used for complementary treatment in many 
countries such as Amazonia, Barbados, Borneo, Brazil, Cook Islands, Curacao, Dominica, Guatemala, Guam, Guyana, Haiti, Jamaica, Madagascar, Malaysia, Peru, Suriname, Togo and West Indies, ${ }^{11,12,13}$ as well as in Uganda. ${ }^{7}$ It is hoped that traditional medicine will in future provide the cure to many tropical diseases that have defied orthodox prescriptions. The objective of this study was therefore to undertakephytochemical composition analysis using GC-MS on the ethanolic extracts of leaves of Annona muricata.

\section{MATERIALS AND METHODS}

\section{Sample collection and authentication}

Fresh leaves of Annona muricata L. were collected from the wild in Eastern Uganda in the district of Kaliro during the month of August 2013. The plant was identified and authenticated in the Makerere University Botanical Herbarium (MHU) by Ms. Olivia Wanyana Mangeni. A voucher specimen was deposited in the herbarium under the collection number GY 021- 10/13- MB 300-0007/12-001.

\section{Samples preparation and Extraction}

The leaves of Annona muricatawere washed with water and cut into small pieces, drying was done at room temperature, and the dried leaves were powdered. $150 \mathrm{~g}$ of powdered leaves were extracted using $500 \mathrm{ml}$ ethanol for three days by the plant tissue homogenization method as previously described. ${ }^{14}$ The extract was then concentrated using a rotary evaporator and kept at $4^{\circ} \mathrm{C}$ until used.

\section{Chemicals and reagents}

All chemicals and reagents were procured from certified suppliers and were of the highest analytical standard.

\section{Gas Chromatography Mass Spectroscopy}

Gas chromatography mass spectroscopy (GC-MS), a hyphenated system which is a very compatible technique and the most commonly used technique for the identification and quantification purpose was used. The unknown organic compounds in the complex mixture can be determined by interpretation and also by matching the spectra with reference spectra.

\section{Preparation of extract}

The ethanolic extract of the leaves was analyzed using Gas Chromatography Mass Spectroscopy for the identification of the phytochemical compounds present. A solvent blank analysis was first conducted using $1 \mu \mathrm{l}$ of absolute ethanol. Then $1 \mu \mathrm{l}$ of the reconstituted ethanolic extract solution was employed for GC-MS analysis as previously described with modifications..$^{15,16}$

\section{Analysis}

GC-MS analysis was carried out on a GC system comprising a Gas Chromatograph interfaced to a Mass Spectrometer (GC-MS) instrument; Schimadzu GCMS-QP2010, employing the following conditions: Column Elite- 1 fused silica capillary column $(30 \times 0.25 \mathrm{~mm}$ ID $\times 1 \mathrm{EM} \mathrm{df}$, composed of $100 \%$ Dimethyl poly siloxane), operating in electron impact mode at $70 \mathrm{eV}$; helium (99.999\%) as carrier gas at a constant flow of $1 \mathrm{ml} /$ minute and a sample injection volume of $1 \mu \mathrm{l}$ which was employed (split ratio of $10: 1$ ) injector temperature $250^{\circ} \mathrm{C}$; ion-source temperature $280^{\circ} \mathrm{C}$. The oven temperature was programmed from $110^{\circ} \mathrm{C}$ (isothermal for 2 minutes), with an increase of $10^{\circ} \mathrm{C} /$ minute, to $200^{\circ} \mathrm{C}$, then $5^{\circ} \mathrm{C} /$ minute to $280^{\circ} \mathrm{C}$, ending with a 9 minutes isothermal at $280^{\circ} \mathrm{C}$. Mass spectra were taken at $70 \mathrm{eV}$; a scan interval of $0.5 \mathrm{~s}$ and fragments from 40 to
$550 \mathrm{Da}$. Total run time was $30 \mathrm{~min}$. The compounds were then identified from the GC-MS peaks, using library data of the corresponding compounds. GC-MS was analyzed using electron impact ionization at $70 \mathrm{eV}$ and data was evaluated using total ion count (TIC) for compound identification and quantification. The spectrums of the components were compared with the database of spectrum of known components stored in the GC-MS library using NISP Search. The relative \% amount of each component was calculated by comparing its average peak area to the total areas. Measurement of peak areas and data processing were carried out by Turbo-Mass-OCPTVS-Demo SPL software.

\section{RESULTS}

Our previous study, ${ }^{7}$ reported that ethanolic leaves extracts of Annona muricata $\mathrm{L}$ showed anticancer and antioxidant activities. The results obtained from this study represented an important step towards the effective characterization of the secondary class metabolite compounds from this plant using GC-MS analysis. Preliminary qualitative phytochemical analysis of extracts revealed it to be rich in secondary class metabolite compounds of alkaloids, saponins, terpenoids, flavonoids, coumarins and lactones, anthraquinones, tannins, Cardiac glycosides, phenols and phytosterols as shown in the Figure 1.

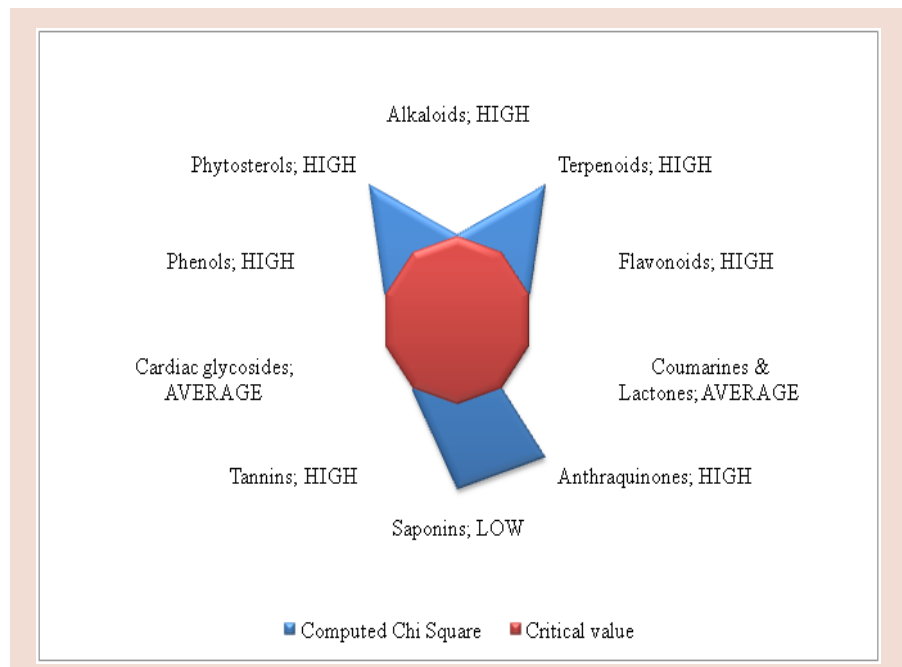

Figure 1: Phytochemicals present in Ethanolic leaves extracts of Annona muricata with relative abundance computed from the $\mathrm{X}^{2}$ Test. $^{7}$

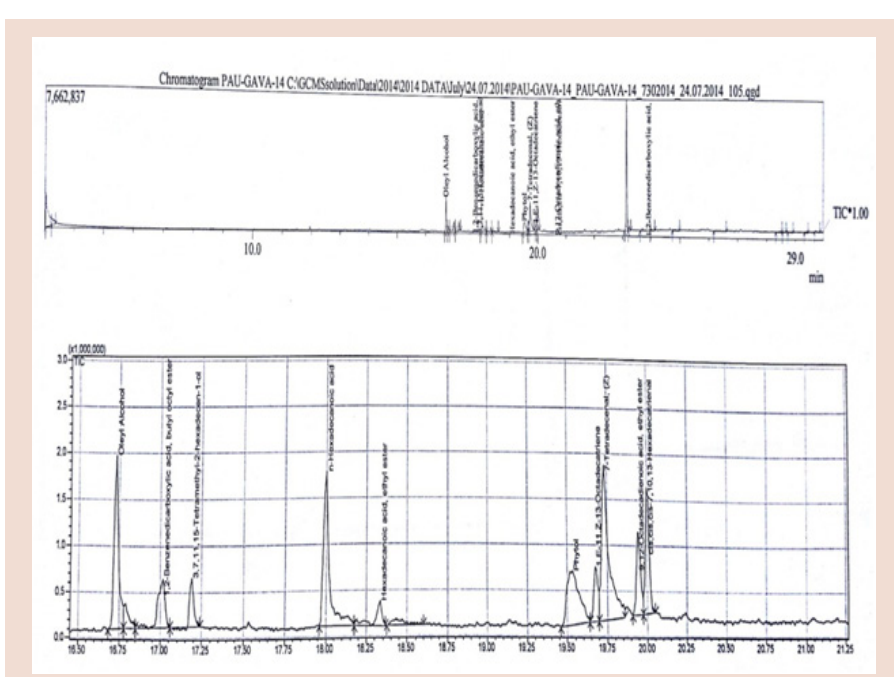

Figure 2: Total lon Chromatogram (TIC) of ethanolic extract of leaves of Annona muricata 
Table 1: Phyto-components generated in the ethanolic leaves extract of Annona muricata by GC-MS Peak Report TIC

\begin{tabular}{|c|c|c|c|c|c|}
\hline Peak \# & $\begin{array}{l}\text { Retention time/ } \\
\text { minutes }\end{array}$ & $\begin{array}{l}\% \text { Composition } \\
\text { by Area }\end{array}$ & $\begin{array}{l}\text { Matched compound } \\
\text { IUPAC Name }\end{array}$ & $\begin{array}{l}\text { Chemical } \\
\text { Formula }\end{array}$ & Comment \\
\hline 1 & 3.034 & 16.8 & - & - & Unidentified \\
\hline 2 & 3.342 & 3.93 & 2-Pentadecanol & $\mathrm{C}_{15} \mathrm{H}_{32} \mathrm{O}$ & Matched \\
\hline 3 & 16.732 & 6.15 & Oleyl Alcohol & $\mathrm{C}_{18} \mathrm{H}_{36} \mathrm{O}$ & Matched \\
\hline 4 & 16.792 & 1.04 & - & - & Unidentified \\
\hline 5 & 17.015 & 2.67 & $\begin{array}{l}\text { 1,2-Benzenedicarboxylic } \\
\text { acid, butyl octyl ester }\end{array}$ & $\mathrm{C}_{20} \mathrm{H}_{30} \mathrm{O}_{4}$ & Matched \\
\hline 6 & 17.19 & 1.37 & $\begin{array}{l}\text { 3,7,11,15-Tetramethyl-2- } \\
\text { hexadecen-1-ol }\end{array}$ & $\mathrm{C}_{20} \mathrm{H}_{40} \mathrm{O}$ & Matched \\
\hline 7 & 17.998 & 7.12 & n-Hexadecanoic acid & $\mathrm{C}_{16} \mathrm{H}_{32} \mathrm{O}_{2}$ & Matched \\
\hline 8 & 18.331 & 1.29 & $\begin{array}{c}\text { Hexadecanoic acid, ethyl } \\
\text { ester }\end{array}$ & $\mathrm{C}_{18} \mathrm{H}_{36} \mathrm{O}_{2}$ & Matched \\
\hline 9 & 18.431 & 0.73 & - & - & Unidentified \\
\hline 10 & 19.531 & 5.61 & Phytol & $\mathrm{C}_{20} \mathrm{H}_{40} \mathrm{O}$ & Matched \\
\hline 11 & 19.678 & 2.15 & $\begin{array}{l}\text { 1,E-11,Z-13- } \\
\text { Octadecatriene }\end{array}$ & $\mathrm{C}_{18} \mathrm{H}_{32}$ & Matched \\
\hline 12 & 19.733 & 9.39 & 7-Tetradecenal, (Z) & $\mathrm{C}_{14} \mathrm{H}_{26} \mathrm{O}$ & Matched \\
\hline 13 & 19.946 & 3.21 & $\begin{array}{l}\text { 9,12-Octadecadienoic } \\
\text { acid, ethyl ester }\end{array}$ & $\mathrm{C}_{20} \mathrm{H}_{36} \mathrm{O}_{2}$ & Matched \\
\hline 14 & 20.003 & 4.26 & $\begin{array}{l}\text { cis, cis, cis-7,10,13- } \\
\text { Hexadecatrienal }\end{array}$ & $\mathrm{C}_{16} \mathrm{H}_{26} \mathrm{O}$ & Matched \\
\hline 15 & 23.143 & 23.51 & - & - & Unidentified \\
\hline 16 & 23.225 & 1.08 & - & - & Unidentified \\
\hline 17 & 23.695 & 1.74 & - & - & Unidentified \\
\hline 18 & 24.025 & 0.75 & $\begin{array}{l}\text { 1,2-Benzenedicarboxylic } \\
\text { acid, diisooctyl ester }\end{array}$ & $\mathrm{C}_{24} \mathrm{H}_{38} \mathrm{O}_{4}$ & Matched \\
\hline 19 & 24.75 & 1.25 & - & - & Unidentified \\
\hline 20 & 26.402 & 1.54 & - & - & Unidentified \\
\hline 21 & 28.35 & 1.12 & - & - & Unidentified \\
\hline 22 & 28.567 & 0.74 & - & - & Unidentified \\
\hline 23 & 28.875 & 0.85 & - & - & Unidentified \\
\hline 24 & 29.331 & 0.74 & - & - & Unidentified \\
\hline 25 & 29.704 & 0.95 & - & - & Unidentified \\
\hline
\end{tabular}

The total ion chromatogram (TIC) of the ethanolic extract, showing the GC-MS profile of the compounds identified is given in Figure 2. The peaks in the chromatogram were integrated and were compared with the database of spectrum of known components stored in the GC-MS NISP library. Phytochemical analysis by GC-MS analysis of the ethanolic extract of leaves of Annona muricata revealed the presence of different fatty acids, heterocyclic compounds, esters among others. 25 peaks were generated.

The detailed tabulations of GC-MS analysis of the extracts are given in Table 1 . From the analysis, 25 compounds have been elucidated for the first time in this study on Annona muricata, of which 12 compounds were effectively matched and identified. The ethanolic extract of the plant generated 25 constituents, the major constituents were at peaks 15 (peak area 23.51\%), Peak 1 (peak area 16.8\%), 7-Tetradecenal, (Z) (peak area 9.39\%), n-Hexadecanoic acid (peak area 7.12\%), Oleryl Alcohol (peak area 6.15\%), Phytol (peak area 5.61\%), cis, cis, cis-7,10,13Hexadecatrienal (peak area 4.26\%), 2-Pentadecanol(peak area 3.93\%), 9,12-Octadecadienoic acid, ethyl ester (peak area 3.21\%), 1,2-Ben- zenedicarboxylic acid, butyl octyl ester (peak area 2.67\%), and 1,E-11,Z13-Octadecatriene (peak area 2.15\%), while the rest had less than $2 \%$ composition by peak area.

\section{DISCUSSION}

The presence of various secondary class metabolites identified puts these results in line with earlier studies that were carried out on the ethanolic seeds extract of Annona muricata, and the phytochemical tests showed that ethanol soursop seeds extract contains secondary metabolites compounds group of saponins, alkaloids and triterpenoids, flavonoids, anthraquinones, tannins, and cardiac glycosides, which they noted that they are defense chemical compounds of plants produced in the plant tissue. ${ }^{16,17}$ The plant could thus be used for the management of various healthy conditions associated with the metabolites screened.

Using GC-MS Analysis, 25 compounds have been elucidated for the first time in our study on Annona muricata, of which 12 compounds were effectively matched and identified. 
1,2-Benzenedicarboxylic acid, butyl octyl ester is a plasticizer compound with antimicrobial, antifouling, antioxidant and hypo-cholesterolemic activities. ${ }^{18} 3,7,11,15$-Tetramethyl-2-hexadecen-1-ol is recorded to have anti-tuberculosis, insecticidal, anti-inflammatory, antioxidant and antimicrobial activities. n-Hexadecanoic acid on the other hand which is commonly known as Palmitic acid has nematicide, pesticide, lubricant, anti-androgenic, flavor, hemolytic 5-alpha reductase inhibitor, antioxidant and hypo-cholesterolemic properties. ${ }^{16}$

Hexadecanoic acid, ethyl ester is a fatty acid ester with nematicide, pesticide, lubricant, anti-androgenic, flavor, and has hemolytic 5-alpha reductase inhibitor properties. ${ }^{19,20}$

Phytol is a diterpene with antimicrobial, anticancer, anti-inflammatory, anti-diuretic, immune-stimulatory and anti-diabetic properties. 9,12-Octadecadienoic acid, ethyl ester is a linoleic acid which has hypocholesterolemic, 5-alpha reductase inhibitor, antihistaminic, insectifuge, anti-eczemic, and anti-acne properties. Finally, 1,2-Benzenedicarboxylic acid, diisooctyl ester is a plasticizer compound with antimicrobial and antifouling properties. ${ }^{15,19,20}$

It is worth noting that of the major constituents identified in our extract, the compounds with the highest composition at peaks 15 (peak area $23.51 \%$ ) and Peak 1 (peak area $16.8 \%$ ) have not been matched in the library. These two could be very novel compounds that need to be analyzed further in order to elucidate their nature. The same applies to the remaining 11 compounds which have not been identified irrespective of their percentage composition being less than $2 \%$.

\section{CONCLUSION}

GC-MS analysis of the ethanolic extract of leaves of Annona muricata revealed the presence of different fatty acids, heterocyclic compounds, esters among others. This confirms the results on presence of the various secondary metabolite compounds detected by the qualitative procedures. These mass spectra are fingerprint of the compound which can be identified from the data library. Hence, the identified phytocomponents using GC-MS can be used as a pharmacognostical tool for the identification of adulterants. The current pioneering study suggests that ethanolic extract is a potent therapeutic agent. It paves the way for the development of several treatment regimens based on this extract. In addition, further research is necessary to identify and purify the active compounds responsible for therapeutic activity, as well as the unidentified compounds.

\section{ACKNOWLEDGEMENTS}

This work forms part of Yahaya Gavamukulya's MSc Thesis work. We thank the Pan African University Institute for Basic Sciences, Technology and Innovation, as well as Cairo University and Makerere University for the financial support and all the work that was conducted in the respective institutions. Final thanks are extended to the Uganda Directorate of Government Analytical Laboratory for the concluding parts of the work which were conducted there.

\section{CONFLICT OF INTEREST}

The authors declare that there is no conflict of interest.

\section{SOURCE OF SUPPORT}

Supported by the Pan African University of the African Union Commission through the Graduate Scholarship Student Research Funding Lot 2013/2014 at the Institute for Basic Sciences, Technology and Innovation in collaboration with Cairo University to Y Gavamukulya.

\section{AUTHOR'S CONTRIBUTIONS}

All authors contributed immensely towards the research work and development of the manuscript. YG-designed experiment, collected samples, conducted laboratory analysis, analyzed data, participated in write-up of manuscript. FA-participated in the design, analysis, write up and reviewed drafts of the manuscript. FW-participated in the design,coordination, analysis, write up and reviewed drafts of the manuscript. EHA -participated in the design and coordination of the study, data interpretation and write-up of manuscript. All authors read and approved the final manuscript.

\section{REFERENCES}

1. Fabricant D, Farnsworth $N$. The value of plants used in traditional medicine for drug discovery. Environmental Health Perspectives 2001; 109(1): 69-75.

2. Wamidh HT. Anticancer and Antimicrobial Potential of Plant-Derived Natural Products. In: Iraj Rasooli, ed. Phytochemicals-Bioactivities and Impact on Health, Croatia; 2011. 141-58.

3. Alviano D, Alviano A. Plant extracts: search for new alternative to treat microbial diseases. Current Pharmaceutical Biotechnology 2009; 10(1): 106-21.

4. Cheng JT. Drug therapy in Chinese traditional medicine. J Clin Pharmacol. 2000; 40(5): 445-50

5. El-Shemy HA, Aboul-Enein AM, Aboul-Enein KM, Fujita K. Willow leaves Extracts Contain Anti-Tumor Agents Effective against Three Cell Types. Plos One. 2007; 2(1): e178.

6. Souza G, Hass A, Poser G, Schapoval E, Elisabetsky E. Ethnopharmacological studies of antimicrobial remedies in the south of Brazil. Journal of Ethnopharmacology 2004; 90(1): 135-43

7. Gavamukulya Y, Abou-Ellela F, Wamunyokoli F, El-Shemy HA. Phytochemical screening, anti-oxidant activity and in vitro anticancer potential of ethanolic and water leaves extracts of Annona muricata (Graviola). Asian Pac J Trop Med. 2014; 7(1): S355-63

8. Thirumal M, Kishore G, Prithika R, Das S, Nithya G. In vitro anticancer activity of Tecomastans (L.) ethanolic leaves extract on human breast cancer cell line (mcf-7). International Journal of Pharmaceutical, Chemical and Biological Sciences 2012; 2(4): 488-93.

9. Lans CA. Ethnomedicines used in Trinidad and Tobago for urinary problems and diabetes mellitus. J Ethnobiol Ethnomedicine 2006; 2(1): 45-55.

10. Hamizah S, Roslida AH, Fezah O, Tan KL, Tor YS, Tan Cl. Chemo preventive Potential of Annona muricata L Leaves on Chemically-Induced Skin Papillomagenesis in Mice. Asian Pacific Journal of Cancer Prevention 2012; 13(6): 2533-9.

11. Schultes RE, Raffauf. The Healing Forest: Medicinal and Toxic plants of the Northwest Amazonia. Portland: R. F. Dioscorides Press; 1990.

12. Morton JF. Caribbean and Latin American Folk Medicine and its Influence in the United States. Q. J. Crude Drug Res. 1980; 18(2): 57-75.

13. Haddock RL. Some medicinal plants of Guam including English and Guamanian common names. Report Regional Tech Mtg Med Plants Papeete, Tahiti, Nov, 1973; South Pacific Commission, Noumea, New Caledonia; 1974. 79.

14. Tiwari P, Bimlesh K, Kaur M, Kaur G, Kaur H. Phytochemical screening and Extraction: A Review. Internationale Pharmaceutica sciencia. 2011; 1(1): 98-106.

15. Paranthaman R, Praveen KP, Kumaravel S. GC-MS Analysis of Phytochemicals and Simultaneous Determination of Flavonoids in Amaranthus caudatus (Sirukeerai) by RP-HPLC. J Anal Bioanal Tec. 2012; 3(1): 147.

16. Komansilan A, Abadi AL, Yanuwiadi B, Kaligis DA. Isolation and Identification of Biolarvicide from Soursop (Annona muricata Linn) Seeds to Mosquito (Aedes aegypti) Larvae. International Journal of Engineering \& Technology IJET-IJENS. 2012; 12(03): 28-32.

17. Ukwubile CA. Phytochemical Screening and Anti-Ovarian Cancer Properties of Annona muricata Linn (Annonaceae) Seed Ethanol Extract. International Journal of Pharmaceutical Frontier Research, IJPFR. 2012; 2(3): 9-17.

18. Sathish SS, Janakiraman N, Johnson M. Phytochemical Analysis of Vitexaltissi- 
ma L. using UV-VIS, FTIR and GC-MS. International Journal of Pharmaceutical Sciences and Drug Research 2012; 4(1): 56-62.

19. Venkata-Raman B, Samuel LA, Pardha SM, Narashimha RB, Naga VKA, Sudhakar M, et al. Antibacterial, Antioxidant Activity And Gc-Ms Analysis of Eupato- rium odoratum. Asian J Pharm Clin Res. 2012; 5(Suppl 2): 99-106.

20. Aneesh TP, Thomas E, Thomas DG, Anandan R. GC-MS Analysis of phytochemical compounds present in the rhizomes of Nerviliaaragoana GAUD. Asian J Pharm Clin Res. 2013; 6(Suppl 3): 68-74.

\section{ABOUT AUTHORS}
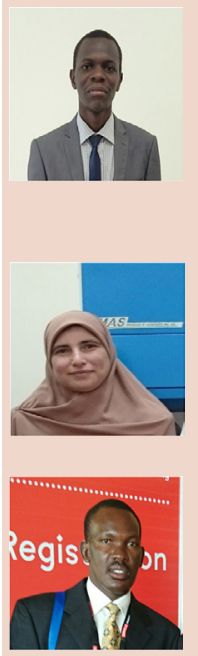

Faten Abou-Ellela: Is a Professor of Biochemistry in the Faculty of Agriculture at Cairo University in Egypt. Her research interests are in cancer research and biotechnology of natural products. She has authored very many papers in the above field in international peer reviewed journals.

Yahaya Gavamukulya: Holds and MSc in Molecular Biology and Biotechnology and Pioneer Graduate Researcher from the Pan African University. Has research interests in natural products research focusing on cancer management. Has so far published one paper on anticancer activities of Annona muricata, and an MSc Thesis on the same. Is currently a Lecturer of Biochemistry and Molecular Biology at The Busitema University Medical School in Uganda.

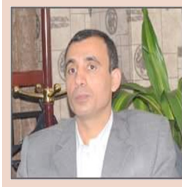

Fred Wamunyokoli: Is an Associate Professor of Biochemistry at Jomo Kenyatta University of Agriculture and Technology, Nairobi Kenya (JKUAT). His research interests are in cancer research and development of novel treatment therapies for cancer. Is currently lecturing at JKUAT, The Pan African University and visiting fellow at the National Institute of Health in the USA. He also serves as The Director School of Open Distance and e-Learning (SODel) at JKUAT.

Hany A El-Shemy: Is a distinguished Professor of Biochemistry steeped towards modern biotechnology for food security and natural products for diseases management. Has published more that 60 international peer reviewed papers in the above fields. Is currently the Vice President of the Egyptian Academy for Scientific Research, and Dean Faculty of Agriculture, Cairo University, as well as a visiting scholar in many Universities and Research centers all over the globe.
\end{abstract}

